\title{
O Brasil na guerra das Malvinas: rediscutindo as motivações da política de "neutralidade imperfeita" do governo João Figueiredo (1982)
}

Brazil in the Falklands War: re-discussing the motivations of the João Figueiredo government's "imperfect neutrality" policy (1982)

Brasil en la Guerra de las Malvinas: replanteamiento de las motivaciones de la política de "neutralidad imperfecta" del gobierno de João Figueiredo (1982)

Tiago Monteiro

tiagobenin@yahoo.com.br Doutor em História (UFRJ). Professor da Prefeitura da Cidade do Rio de janeiro (SME) e da Pós-graduação da Universidade Estácio de Sá (UNESA) - Brasil https://orcid.org/0000-0002-6855-2341

\section{RESUMO}

O objetivo desse trabalho é analisar as razões que levaram o Brasil a ter uma franca posição pró-Argentina na Guerra das Malvinas (1982). Nossa linha de trabalho considera que o general João Figueiredo - então presidente de uma Brasil sob o julgo ditatorial - e sua equipe foram motivadas pela crença de que uma derrota humilhante por parte dos argentinos abriria espaço para o fortalecimento das esquerdas no país, as quais ameaçariam a ordem interna do Brasil. Acreditamos também que uma das origens fundamentais de tais ideias foi a "comunidade de informações", cuja produção será aqui estudada.

Palavras-chaves: Malvinas, ditadura-militar, Comunidade de informações.

\section{ABSTRACT}

The objective of this work is to analyze the reasons that led Brazil to have a frank pro-Argentine position in the Falklands War (1982). Our line of work considers that General João Figueiredo - then president of a Brazil under the dictatorial judgment - and his team were motivated by the belief that a humiliating defeat on the part of the Argentines would open space for the strengthening of the left in the country, which would threaten the internal order of Brazil. We also believe that one of the fundamental origins of such ideas was the "information community", whose production will be studied here.

Keywords: Falklands War, military dictatorship, information community.

\section{RESUMEN}

El objetivo de este trabajo es analizar las razones que llevaron a Brasil a tener una posición francamente pro argentina en la Guerra de las Malvinas (Conflicto del Atlántico Sur) (1982). Nuestra línea de trabajo considera que el general João Figueiredo -entonces presidente de un Brasil bajo juicio dictatorial- y su equipo estaban motivados por la creencia de que una derrota humillante de los argentinos abriría espacios para el fortalecimiento de la izquierda en el país, lo que amenazaría el orden interno de Brasil. También creemos que uno de los orígenes fundamentales de tales ideas fue la "comunidad de la información”, cuya producción se estudiará aquí.

Palabras clave: Malvinas, dictadura militar, comunidad de la información.

\section{INTRODUÇÃO}

$\mathrm{Na}$ madrugada de 02 de abril de 1982, tropas argentinas invadiram e ocuparam o arquipélago das Malvinas, também conhecidas como Ilhas Falklands. No dia seguinte unidades militares da Argentina também tomaram posse das ilhas Georgias e Sandwich do Sul, que, assim como as Malvinas, eram possessões do Reino Unido. 
Liderados pela primeira-ministra Margareth Thatcher, do Partido Conservador (Conservative Party), o governo britânico reagiu rompendo suas relações diplomáticas com a Argentina, congelando os bens argentinos depositados em bancos nacionais, e organizando uma força tarefa destinada a retomar militarmente os territórios ocupados. As ações britânicas e da Argentina iniciaram a chamada Guerra das Malvinas (ou Falklands War), que durou até a rendição argentina em junho de 1982.

As ilhas Malvinas estão localizadas a menos de $500 \mathrm{~km}$ do litoral argentino e foram disputadas pelos impérios espanhol e britânico ao longo dos séculos XVIII e XIX. Em 1833, a marinha britânica ocupou o arquipélago em detrimento da recém-independente República Argentina sob o argumento de que seus navegadores foram os responsáveis pela descoberta do arquipélago no século XVI. Os ingleses desejavam controlar territórios estratégicos para as embarcações que navegavam para o oceano Pacífico a partir do sul do oceano Atlântico.

Nessa conjuntura, a Argentina passava por um momento de elevada instabilidade interna e fragilidade internacional. Todavia, essa situação foi revertida no final do século XIX e os presidentes e suas equipes empossados a partir desse novo momento se empenharam em modificar tal quadro por vias político-diplomáticas. Tais esforços levaram a Organização das Nações Unidas (ONU) a criar um comitê para arbitrar esse litígio em 1965 e ele organizou reuniões com as partes envolvidas. Autoridades argentinas e britânicas também debateram em outros encontros bilaterais e a resolução da questão das Malvinas continuava em um impasse quando um golpe de Estado foi deflagrado na Argentina no dia 24 de março de 1976. Os comandantes das forças armadas argentinas lideraram essa insurreição e organizaram um regime ditatorial autodenominado Proceso de Reorganización Nacional (PRN). Os responsáveis pela política externa do PRN adotaram estratégias de maior agressividade e confrontação em relação aos britânicos, os quais também passaram a agir de forma análoga. Esse quadro resultou na suspensão das relações diplomáticas entre ambos os governos entre 1976 a 1979 (MARTINEZ, 1983, p.98-106) (ESPÓSITO NETO, 2006, p. 62-79).

Paralelamente ao período de ausência de negociações com Londres, os dirigentes do PRN montaram uma implacável estrutura repressiva responsável pelo sequestro, tortura e morte de milhares de pessoas, desmantelaram as organizações sindicais, limitaram as atividades partidárias e adotaram políticas econômicas baseadas na escola monetarista - também conhecida como ortodoxa ou neoliberais. As ações dos líderes do PRN visavam reorganizar totalmente a Argentina, mas o saldo dessas medidas foram o assassinato de milhares de indivíduos, caos social, recessão, desemprego e aumento das vozes contrárias ao status quo. Em tal situação, em março de 1981 general Roberto Viola assumiu a presidência. Ele buscou governar com o apoio dos partidos conservadores a fim de viabilizar uma Transição negociada para o fim da ditadura. Outras iniciativas do general Viola eram a adoção de políticas neoliberais moderadas e uma maior predisposição de negociar com os britânicos de forma diplomática a posse das Malvinas. O projeto do governo Viola desagradou importantes camadas do PRN, os quais organizaram um golpe interno e colocaram na presidência um dos principais idealizadores da conjuração, o general Leopoldo Galtieri.

O governo Galtieri interrompeu os trabalhos da administração anterior e pôs em prática ações como a retomada das políticas ortodoxas no campo econômico e um afastamento dos líderes partidários. No que diz respeito à política exterior, abandonou o pluralismo restrito adotado pelo general Viola e assumiu uma postura de alinhamento incondicional em relação aos Estados Unidos (EUA), então governados por Ronald Reagan. Por conseguinte, a Argentina adotou um discurso anticomunista nos fóruns internacionais, prontificou-se em enviar oficiais experientes na repressão interna para apoiar as operações militares estadunidenses em países da América Central, mostrou-se interessada em discutir a possibilidade de fazer parte de aliança militar com a África do Sul sob o julgo do sistema racista do apartheid a fim de fazer frente ao apoio cubano ao governo socialista de 
Angola. Essas medidas foram bem recebidas nos EUA, por organizações conservadoras do mundo e até mesmo pelo núcleo principal do governo Thatcher (MARTINEZ, 1983, p. 106-114).

O general Galtieri e seus aliados tinham consciência do pouco apoio que contavam no interior da sociedade argentina, da oposição que suas propostas econômicas despertariam e de outros fatores que desgastavam a manutenção do PRN. Por esses e outros motivos concluíram que a recuperação das Malvinas através de uma campanha militar resolveria todos esses problemas e ainda forneceria legitimidade para o futuro pois, entre outros motivos, a sociedade argentina em geral desejava o reestabelecimento da soberania de tal arquipélago. Igualmente, as operações de guerra uniriam o país em torno do presidente, desviariam as atenções dos problemas pelos quais a ditadura e a Argentina passavam e embasariam o discurso de que as forças armadas (FFAA) estavam recuperando a honra do país.

O almirante Jorge Isaac Anaya - comandante-em-chefe da armada de guerra e um dos principais articuladores da deposição do general Roberto Viola - foi um dos principais ideólogos desse projeto. Anaya e os demais estrategistas do PRN planejaram a expedição militar baseados em numerosas crenças. Primeiramente, consideravam que os EUA ficariam neutros por três razões. A primeira era que o presidente Reagan não colocaria em risco a aliança com os argentinos contra as guerrilhas de orientação socialista na América Central. A segunda era que os EUA possuíam obrigações militares com os britânicos e com os Argentinos. Assim, a única opção era a neutralidade. Por fim, achavam que os estadunidenses obrigariam seus aliados a negociarem em detrimento do conflito, o qual enfraqueceria suas posições diante da União Soviética (URSS) e demais membros do chamado "Bloco Socialista".

A cúpula militar argentina também imaginava que o governo Thatcher procuraria o caminho da negociação porque não estaria disposto a custear uma guerra em uma região tão distante e pouco rentável. Afinal, anos antes os conservadores haviam reduzido o orçamento militar. Outro fator desse raciocínio era de que as dificuldades logísticas decorrentes das enormes distâncias que as tropas britânicas teriam que percorrer até o teatro das operações também desencorajariam uma reação bélica. Igualmente, havia a ideia de que a opinião pública britânica se colocaria contra a guerra em virtude da possibilidade da morte de inúmeros soldados por um arquipélago inexpressivo. Outros fatores que guiaram o pensamento dos chefes militares do PRN era a confiança de que a ONU, a Organização dos Estados Americanos (OEA), a igreja Católica, os EUA e países europeus tradicionalmente aliados e/ou clientes da Argentina iriam pressionar pelo acordo negociado (LOPES, 2012, p. 123).

Assim, os dirigentes argentinos organizaram a campanha militar que visava surpreender os britânicos, desencorajar os últimos a lutar a partir do estabelecimento de posições bélicas bem defendidas e obrigar o governo de Thatcher a negociar em desvantagem. Porém, a movimentação de tropas e suprimentos por parte da Argentina foi detectada pelos serviços de informações de países como os EUA, cujo presidente tentou convencer Galtieri a desistir da empreitada. O governo britânico também foi notificado, mas não tomou contramedidas e tal postura resultou em críticas por parte de parcelas da oposição.

Contudo, diferentemente dos planos de Galtieri e Anaya, os britânicos reagiram com firmeza: convocaram uma sessão extraordinária do Conselho de Segurança da ONU no mesmo dia da ação argentina e conseguiram aprovar uma resolução condenando Buenos Aires. Paralelamente, começaram a organizar uma força tarefa para fazer frente às FFAA argentinas. Diante de tais fatos, o governo brasileiro, então encabeçado pelo general João Figueiredo, declarou sua neutralidade no conflito nascente. Mas, diferente de outros países, o Brasil esteve neutro formalmente uma vez que na prática tomou várias medidas favoráveis à Argentina e essa postura tem sido conhecida como neutralidade imperfeita ou neutralidade ativa. 
As motivações dessa estratégia brasileira têm sido examinadas desde a capitulação argentina e o objetivo desse trabalho é contribuir com essa tradição de estudos a partir do exame de documentos produzidos pelos serviços de informação do Brasil. A hipótese que permeará esse artigo é que para as autoridades brasileiras uma derrota humilhante da Argentina favoreceria as esquerdas locais, colocaria o país na órbita da URSS e tais fatos desestabilizariam as Américas em geral e, em especial, o Brasil. O governo Figueiredo e o aparelho de informações chegaram a essa conclusão a partir do exame das relações estabelecidas entre o PRN e a URSS, as quais eram vistas como uma ameaça à estabilidade continental.

As metas desse trabalho serão atingidas a partir da execução das seguintes etapas: (1) estudaremos as relações Argentina-Brasil no período anterior à guerra das Malvinas; (2) discutiremos o comportamento do governo do general João Figueiredo em tal conflito juntamente com uma apresentação das principais obras dedicadas a entender tais medidas; (3) investigaremos o material produzido pelos órgãos de informação e suas conclusões acerca da natureza do PRN e, por fim, (4) estudo das relações entre a Argentina e a URSS e a percepção dos agentes brasileiros sobre tais vínculos; (5) apresentaremos as discussões com o governo Reagan e nossas contribuições em tais assuntos.

\section{PROCEDIMENTOS METODOLÓGICOS}

Esse trabalho será elaborado segundo os seguintes procedimentos metodológicos: realizamos, em primeiro lugar, uma pesquisa bibliográfica relativa às relações entre a Argentina e o Brasil selecionando aqueles que abordam o tema do posicionamento brasileiro no conflito das Malvinas. Estudamos textos de memórias de autoridades envolvidas no conflito - Guerreiro (1992), Méndez (1993) e Camilión (1999) -; dissertações de mestrado - Walsh (1997) e Espósito Neto (2006) - bem como livros e artigos que estão elencados nas referências bibliográficas. Percebemos no decorrer dessas leituras e análises que a influência do aparato de informações e segurança da ditadura brasileira foi um ponto ausente ou pouco explorado nessas reflexões. Por esses motivos, resolvemos contribuir com essa tradição de trabalhos abordando como a documentação produzida pelos organismos de vigilância e repressão no Brasil orientou os líderes brasileiros nos eventos em questão.

A criação, a organização e as funções dos chamados "órgãos de informações e segurança" da ditadura militar brasileira serão discutidas com maior profundidade no item 4 desse artigo. Assim, nesse tópico metodológico, cabe-nos apontar as estratégias de coleta de dados. Em primeiro lugar, realizei buscas no banco de dados do Arquivo Nacional ${ }^{1}$, instituição responsável pelo acervo produzido pelo aparato repressivo que foi disponibilizado ao público. Afinal, no contexto em que eles foram produzidos, os documentos eram secretos e, por conseguinte, de acesso restrito. Utilizamos "Argentina", "Malvinas" e "Falklands" como palavras-chaves e estudamos o conjunto de relatórios, telegramas, informes e outros tipos de materiais produzidos tendo como critério de seleção os documentos direcionados às altas autoridades da República brasileira. Observamos também as datas em que foram produzidas e, em seguida, examinamos as publicações da imprensa na mesma conjuntura a fim de perceber singularidades e divergências entre os discursos da cúpula ditatorial e a linguagem empregada pelos civis e militares lotados nos órgãos de informação.

Pesquisamos também matérias e notícias de jornais do período em questão a partir dos mesmos critérios de análise empregados para os documentos sigilosos. Contudo, estudamos esse

1 Os documentos digitalizados podem ser consultados no banco de dados do Arquivo Nacional: https://sian.an.gov.br/sianex/consulta/login.asp Acesso em 15 mar. 2021. 
acervo cientes das diferenças entre esses materiais: os jornais e revistas não eram de circulação restrita, eram mercadorias e tinham como meta informar a população segundo a linha editorial de sua respectiva empresa. ${ }^{2}$

No decorrer dessa pesquisa, percebemos que os analistas do aparelho de vigilância também se detiveram em avaliar as relações internacionais argentinas com os países socialistas. Assim, passamos a examinar os casos sobre esse tema e percebemos que a forma como esse grupo de assessoria presidencial observou o sistema político argentino e a possibilidade de uma guinada à esquerda orientou seus relatórios direcionados às altas esferas do governo do general João Figueiredo. Esses, por sua vez, repercutiram tais orientações em suas práticas governamentais, como apontaremos no decorrer desse trabalho.

Desta forma, trabalharemos examinando diferentes fontes e dados. No que diz respeito aos conceitos empregados, eles serão apresentados e discutidos no corpo do texto.

\section{AS RELAÇÕES ENTRE A ARGENTINA E O BRASIL NOS ANOS ANTERIORES À GUERRA DAS MALVINAS}

As relações político-diplomáticas entre a Argentina e o Brasil foram marcadas pela presença de longos períodos de tensões, desconfianças e rivalidades mútuas intercaladas com fases de colaboração no espaço de tempo compreendido entre a independência de ambos os países, meados do século XIX, e meados da década de 1970. Esse panorama começou a ser modificado a partir de iniciativa de dirigentes de ambos os países.

No lado brasileiro, os chefes ditatoriais buscavam manter elevados as taxas de crescimento econômico do país a partir de ações como o aumento da exportação de manufaturados para a Argentina. Outra meta era o interesse em viabilizar a usina hidrelétrica de Itaipu, cuja construção era questionada por Buenos Aires com o argumento de que ela prejudicaria seu país, por meio de acordos bilaterais. Os brasileiros também acreditavam que o incremento dos laços econômicos favoreceria a estabilização do governo da PRN e da sociedade argentina. Os chefes do PRN, por sua vez, concordavam em se colaborar com o Brasil na área repressiva - por meio de operações conjunta e na troca de dados sobre adversários de ambas as ditaduras -; no desenvolvimento nuclear e na formação de uma causa em comum contra as pressões realizadas pelo governo Jimmy Carter (EUA), o qual desejava que ambas as ditaduras sul-americanas respeitassem os direitos de seus presos políticos. Por outro lado, os argentinos estavam divididos entre aqueles que eram favoráveis a políticas de confrontação com o Brasil e outros que defendiam a aproximação. Os últimos conseguiram maiores avanços e tinham como expoente o político e advogado Oscar Camilión, um dos dirigentes do Movimiento de Integración y Desarrollo (MID) e que estava exercendo a função de embaixador no Brasil.

Camilión admirava o modelo econômico adotado pela ditadura brasileira, era ciente do quadro de inferioridade econômica e diplomática de seu país perante o Brasil e temia que a Argentina ficasse isolada na região em um momento em que disputava com o Chile a soberania de ilhas no canal do Beagle, localizadas no extremo sul das Américas. Assim, empenhou-se em resolver as contendas relativas ao aproveitamento dos rios da bacia platina, em estabelecer contratos equitativos na área econômica - a fim de evitar que a Argentina se tornasse um mercado das

${ }^{2} \mathrm{O}$ acervo dos principais jornais e revistas do período estão localizados no setor Hemeroteca da Biblioteca Nacional (BN), sediada na cidade do Rio de Janeiro. Parte dessa documentação está digitalizada e pode ser consultada na hemeroteca digital: http://bndigital.bn.gov.br/hemeroteca-digital/ Acesso em 15 mar. 2021. 
exportações de bens industriais brasileiros -; em fazer mais parcerias econômicas, técnicas e científicas com o Brasil, entre outras atividades (Z4 REX IPS 39, 22.03.1973, p. 83-85) (Z4 REX IPS 40, 31.07.1973, p. 119-121.) (JB, 22.05.1976, p. 08 [a]) (JB, 22.05.1976, p. 08 [b]) (Z4 REX IPS 41, 24.04.1980, p. 118-128.) (BANDEIRA, 1995, p.135-137).

A posse do general João Figueiredo e do diplomata Ramiro Saraiva Guerreiro como ministro das Relações Exteriores facilitaram os entendimentos entre Brasília e Buenos Aires uma vez que os argentinos desconfiavam das autoridades do governo brasileiro anterior, como o presidente Ernesto Geisel e o ministro Antônio Azeredo da Silveira. Assim, em outubro de 1979, foi assinado o Acordo Tripartite Corpus-Itaipu (Acuerdo Multilateral sobre Corpus-Itaipu), que resolveu de forma amigável a questão da utilização do potencial hidrelétrico do rio Paraná a partir de clausulas em que a construção da hidrelétrica Itaipu não impediria a construção da hidrelétrica argentina de Corpus. Posteriormente foram estabelecidos de acordos de cooperação nuclear, comercial e tecnológico. Ambos os países rejeitaram a proposta estadunidense de boicotar os soviéticos após os últimos terem invadido o Afeganistão (1979) e votavam nas mesmas resoluções na OEA e na ONU (JB, 30.01.1977, p. 06 Cad. Especial) (JB, 02.07.1978, p. 14) (JB, 17.01.1980, p. 21) (N8_PSN_EST_0288.1972-1980,p.1175-1181).

O bom nível de relacionamento entre os dois países levou o general Figueiredo a realizar uma visita oficial à Argentina em maio de 1980, a primeira de um presidente brasileiro desde 1935. Em agosto do mesmo ano, o general Jorge Videla, presidente da Argentina, retribuiu a visita de Figueiredo. Em ambas as reuniões, os presidentes criticaram o protecionismo das nações industrializadas, defenderam os acordos bilaterais até então assinados e criticaram a ingerência internacional sobre países soberanos. Em fevereiro de 1981, Camilión deixou a embaixada no Brasil para assumir o ministério das Relações Exteriores. Nessa nova função, ele permaneceu aplicando a política de aproximação com o Brasil, o que resultou, por exemplo, no encontro entre os presidentes e generais Figueiredo e Viola na fronteira da Argentina e Brasil em maio de 1981.

A deposição do general Roberto Viola e a ascensão do general Leopoldo Galtieri à presidência da Argentina em dezembro de 1981 colocou em aparente suspensão os intentos de proximidade e cooperação. Uma das razões desse quadro foi que a nova administração atraiu para sua órbita os setores da sociedade argentina críticos aos tratados e acordos com o Brasil por acreditarem que eles eram lesivos à Argentina. Igualmente, o novo ministro argentino das Relações Exteriores, Nicanor Costa Méndez, era contrário ao universalismo da administração anterior e buscava fazer do país o aliado prioritário dos EUA também através do intercâmbio comercial, o que possivelmente afetaria os interesses econômicos brasileiros.

Todavia, apesar desses fatos, Costa Méndez fez uma visita oficial ao Brasil em março de 1982 a convite do ministro Saraiva Guerreiro. Nessa ocasião, ele se encontrou com o presidente Figueiredo e falou, em discursos, do interesse do governo Galtieri em dar continuidade aos entendimentos com os brasileiros (VIDIGAL, 2011, p. 10-12)

Desta forma, o padrão de relacionamento entre os governos Figueiredo e Galtieri não estava plenamente definido quando houve a invasão das Malvinas. Porém, uma vez informado do ataque, o governo João Figueiredo se pronunciou condenando as ações bélicas ao mesmo tempo em que declarou seu apoio ao direito argentino de ter a soberania sobre o arquipélago. Nos dias seguintes, os líderes brasileiros criaram linhas de créditos especiais para empresas argentinas e orientou que as transportadoras brasileiras exportassem produtos argentinos como seus a fim de burlar o boicote comercial e financeiro promovido pelos aliados do Reino Unido como os EUA e a Comunidade Econômica Europeia (CEE) - uma organização econômica composta por países como o Reino Unido, a França e a Alemanha Ocidental. O Brasil também passou a privilegiar a importação de produtos argentinos para ajudar financeiramente tal país e afirmou que 
disponibilizaria seus portos aos argentinos em caso de um eventual bloqueio naval britânico (JB, 12.04.1982, p. 12) (JB, 13.04.1982, p. 08) (JB, 03.06.1982, p. 13).

No campo diplomático, o governo Figueiredo enviou mensagens para o general Galtieri e para a primeira-ministra Thatcher sugerindo moderação nas negociações. Igualmente, orientou seu embaixador no Reino Unido, Roberto Campos, e na Argentina, Carlos F. Duarte Gonçalves da Rocha, para que ambos se empenhassem em obter um cessar fogo e, em seguida, uma paz perpétua, negociada e satisfatória para ambos os beligerantes. O Brasil também exerceu a função de protetor dos interesses argentinos no Reino Unido e tomou posições pró-Argentina nas reuniões de emergência que aconteceram na OEA e na ONU.

As autoridades brasileiras cederam dois aviões Embraer EMB-111 (Bandeirante Patrulha), cuja função era o patrulhamento litorâneo. Extraoficialmente, elas também colaboraram com negociações e com aquisições de armas e outros equipamentos militares comprados de forma clandestinas por parte dos argentinos (GUERREIRO, 1992, p. 111) (BANDEIRA, 1995, p. 267) (LOPES, 2012, p.129-133). O Brasil também reteve em junho de 1982 o bombardeiro britânico Avro Vulcan que sofreu pane e fez um pouso de emergência no Rio de Janeiro. O destino dessa aviação motivou uma controvérsia porque os argentinos pediram que o bombardeiro ficasse retido até o fim da guerra e os britânicos solicitaram a liberação imediata do Avro Vulcan. O governo brasileiro negociou com os beligerantes e o acordo final foi que o bombardeiro seria desarmado, liberado e os britânicos se comprometeram a não mais usá-lo na guerra (GUERREIRO, 1992, p. 111) (EL PAÍS, 22.04.2012).

Esse evento fez com que membros do governo Thatcher reclamassem do fato de que a Força Aérea Brasileira (FAB) tenha aprisionado o Avro Vulcan, mas permitia a escala de aviões argentinos com fins militares. Em resposta a essa reclamação, os brasileiros negaram que a natureza militar dos voos argentinos (EL PAIÍS, 22.04.2012).

Paralelamente a esse conjunto de procedimentos por parte do Brasil, não se concretizavam as estimativas do governo Galtieri. Embora em um primeiro momento os EUA tenham trabalhado por uma solução negociada, posteriormente a administração Reagan se colocou ao lado dos britânicos e passou a colaborar ativamente com eles através, por exemplo, do envio de informações colhidas pelos satélites estadunidenses. A ONU e as outras instituições internacionais não conseguiram influenciar nas decisões belicosas de Margareth Thatcher e a Argentina não estava preparada militar e tecnologicamente para enfrentar uma longa campanha militar contra o poderio britânico.

Diante dessa situação desfavorável, as autoridades do governo Galtieri se voltaram para o Movimento dos Países Não-Alinhados (MNA), organização formada a partir da Conferência ÁsiaÁfrica (1955) por países recém independentes e outros que decidiram não se alinhar a uma das duas superpotências da Guerra Fria (1947-1991). A Argentina ingressou nesse organismo em 1973, mas os dirigentes ditatoriais que assumiram o poder em 1976 se afastaram dela. Mas, no decorrer dos combates, os líderes do Não Alinhados apoiaram a Argentina e se colocaram na linha de frente da pressão diplomática contra os britânicos. Em contrapartida, o general Galtieri e o ministro Costa Méndez abandonaram suas manifestações profundamente anticomunistas e pró-EUA e adotaram o discurso do MNA como a defesa da autodeterminação dos povos, a crítica às políticas de Israel e da África do Sul racista (LECHINI, 2006, p. 39).

Países vinculados aos Não-Alinhados auxiliaram militarmente a Argentina. Por exemplo, de acordo com a documentação produzida pelos serviços de informação do Brasil e do Reino Unido, as autoridades brasileiras autorizaram que aviões transportando armas para a Argentina aterrissassem em seu território. Esse comércio foi organizado a partir da URSS, contou com o apoio do governo cubano e envolveu não apenas o Brasil, mas também Angola, Peru - que vendeu aviões- 
caça Mirage - Israel e Líbia. Os dois últimos países foram aqueles que mais forneceram equipamentos bélicos para a Argentina.

Essas operações tiveram começaram a ser negociadas em 10 de abril de 1982, a partir da chegada do diplomata cubano Emilio Aragonés Navarro a Buenos Aires. No dia anterior, Navarro e o avião que o transportava foram interceptados por caças da FAB e liberados após 6 horas de negociações em Brasília (Z4 REX IPS 230, 07.07.1982, p. 03-06.) (O GLOBO, 21.04.2012). Esse fato foi noticiado pela imprensa brasileira, mas ainda que seus analistas tenham estranhado o pouso dos cubanos, seus comentários demonstram desconhecimento sobre o real motivo da missão de Emilio Navarro (JB, 11.04.1982, p. 15). Em relação a esse assunto, o governo argentino negou no período que estava recebendo armas da URSS e declarou que as relações eram unicamente no campo comercial (JB, 03.06.1982, p. 13).

O conflito no Atlântico Sul também foi uma pauta importante no encontro entre os presidentes Figueiredo e Reagan em maio de 1982 e analisaremos essa reunião mais adiante.

\section{A "NEUTRALIDADE IMPERFEITA" SEGUNDO A LITERATURA E UMA ANÁLISE DOS TEXTOS DO APARELHO DE INFORMAÇÕES SOBRE A ARGENTINA}

Os fatos e eventos descritos nos últimos parágrafos permitem entender mais profundamente a chamada "Neutralidade Imperfeita": moderada no setor diplomático e completamente pró-argentina nas áreas econômica e militar.

As explicações dessa postura têm sido objeto de variadas reflexões. Em suas memórias, Saraiva Guerreiro afirmou que esse comportamento foi pautado, em primeiro lugar, pela busca da manutenção das boas relações bilaterais com britânicos e argentinos. Em segundo lugar, afirmou que o governo Figueiredo agiu em busca de uma paz que satisfizesse ambos os lados mesmo discordando da solução militar argentina a qual, declarou o diplomata, poderia incentivar outros países a também recorrerem ao uso da força nas questões de litígio. O ex-ministro citou também o esforço de evitar o envolvimento da URSS no conflito, mas de forma bastante marginal (GUERREIRO, 1992, p. 99-113). Segundo Costa Méndez, o Brasil foi motivado pelo fato do governo Figueiredo ter concordado com os argumentos e a posição argentina (MÉNDEZ, 1993, p.201-281). Oscar Camilión apresentou conclusões semelhantes às de Costa Méndez (CAMILIÓN, 1999, p. 281).

Luiz Moniz Bandeira, por sua vez, considerou que o governo brasileiro foi motivado pela meta de suprimir permanentemente a tradicional rivalidade com a Argentina e substituí-la por laços de confiança que consolidaria a política de integração com o país vizinho. Do mesmo modo, o general Figueiredo e seus auxiliares trabalharam para evitar que a Argentina fosse derrotada de forma humilhante pois a concretização de tal quadro desestabilizaria o país e possibilitaria a ascensão de políticos esquerdistas que se aproximariam de Cuba e da URSS (BANDEIRA, 1995, p.265-268). Segundo Marcelo Walsh, o exercício da neutralidade imperfeita" foi motivado pela concordância com a reivindicação argentina, pela meta de superar o sentimento de rivalidade e favorecer a continuidade da integração econômica (WALSH, 1997, p. 41-54) De acordo com Carlos Escudé e Andrés Cisneros, as autoridades brasileiras adotaram as atitudes citadas porque não desejavam o colapso do importante parceiro econômico. Elas também agiram por considerar que a maioria dos países europeus estavam alheios ao conflito anglo-argentino e adotaram sanções contra a Argentina sem fundamentos (ESCUDÉ \& CISNEROS, 2000). 
A importância econômica da Argentina para o Brasil também explica o comportamento do governo Figueiredo para Roberto Lopes. Outros fatores citados pelo autor em questão foram a disposição da diplomacia em questão de preservar o sistema interamericano e de manter seu tradicional apoio à reinvindicação de Buenos Aires, embora não nutrissem simpatia pelas orientações da administração Galtieri (LOPES, 2012, p.133-134). Raúl S. Sanhueza e Daniel F. Filmus concordam que a conduta brasileira na Guerra das Malvinas foi reflexo do fato do país historicamente reconhecer a legitimidade da demanda argentina pelas Malvinas. Além disso, segundo Carvajal, havia o interesse de Brasília em preservar o recém-construído padrão de cooperação em suas relações com a Argentina (SANHUEZA, 2013, p. 63) (FILMUS, 2015, p.348359).

Espósito Neto (2006) e Túlio Ferreira e Clarice Fortes (2020) chegaram a conclusões análogas sobre as causas do envolvimento brasileiro no conflito anglo-argentino. Primeiramente, houve o interesse da cúpula brasileira em fortalecer a integração sul-americana e em preservar o sistema de cooperação recentemente orquestrada com país vizinho. Em segundo lugar, pesou o paradigma da política externa do governo Figueiredo, o chamado "universalismo" ou "terceiromundismo", o qual era baseado na aproximação com os países do "Terceiro Mundo", no não alinhamento com os EUA e as potências capitalistas e na busca pela superação do subdesenvolvimento através de trocas comerciais mais igualitárias entre as nações do mundo. Por outro lado, Ferreira e Fortes destacaram empatia a brasileira em relação à causa argentina - mesmo sem ter endossado a invasão bélica -; e a existência de divergências no interior do governo brasileiro em relação ao caminho a ser seguido pelo país durante a guerra. Essas foram superadas em prol da importância da manutenção de boas relações com Buenos Aires após anos de impasses político-diplomáticos (FERREIRA; FORTES, 2020). Espósito Neto, por sua vez, acentuou que o Brasil via a disputa pelas Malvinas como um conflito de cunho colonial. Desta forma, apoiou Buenos Aires conforme sua tradição de apoiar as lutas descolonizadoras e por acreditar que os argentinos estavam respondendo a agressão feita pelo Reino Unido desde 1833 (ESPÓSITO NETO, 2006, p. 125-166). Diferentemente de Espósito Neto, Carlos Vidigal não entende que a administração brasileira enxergava as disputas pelo arquipélago como uma questão colonial, mas como um problema de soberania. Igualmente, Vidigal salientou que a colaboração com o governo Galtieri teve origem no apoio à reivindicação argentina, na vontade de fortalecer os vínculos político-econômicos e de confiança recém estabelecidos (VIDIGAL, 2011, p. 12-21).

Outros autores refletiram sobre esse tema e chegaram as mesmas linhas explicativas que nós apresentamos anteriormente: o general Figueiredo e sua equipe procederam segundo interesses econômicos, por solidariedade à causa argentina, em razão do temor de que o Brasil seria seriamente prejudicado caso a Argentina fosse arruinada na guerra e pelo interesse em preservar as relações cordiais estabelecidas fazia pouco tempo. A hipótese de que uma derrota humilhante beneficiaria as esquerdas nacionais e o bloco socialista tem recebido pouca atenção e será a partir dessa linha que esse trabalho contribuirá com as discussões sobre as razões da "Neutralidade Imperfeita" por meio do exame de uma série de materiais produzido pelos órgãos de informação da ditadura militar sobre a ditadura argentina. $\mathrm{O}$ estudo desses documentos nos permite entender como os líderes do governo Figueiredo compreendiam o momento pelo qual passava o PRN, os conflitos de interesses que eles identificavam estarem presentes na cúpula civil-militar que governava o país vizinho e como o desenrolar da situação poderia afetar o Brasil. Acreditamos que foi a partir dessas perspectivas que o governo Figueiredo tomou as decisões citadas anteriormente.

Antes de nos aprofundarmos na documentação propriamente dita, cremos que é relevante relembrar que a instalação da ditadura no Brasil, em abril de 1964, foi seguida da reorganização de órgãos de informações que haviam sido fundados para funções como a de auxiliar as decisões dos chefes de Estado ou como dados sobre a defesa nacional. Do mesmo modo, os primeiros dirigentes ditatoriais também investiram na instalação de novas estruturas que além de exercer as funções 
anteriores, passaram também a espionar empresas públicas e privadas, a estudar os problemas nacionais segundo a ótica estatal, a acompanhar as atividades de brasileiros e estrangeiros no exterior e no território nacional, entre outros deveres. Esses organismos foram organizados segundos os preceitos ideológicos dos artificies da ditadura - como a Doutrina de Segurança Nacional (DSN) - e estabelecidos como auxílio de agentes dos EUA e de diversos países da Europa Ocidental.

O Serviço Nacional de Informações (SNI) foi o mais notório da chamada "comunidade de informações". Ele foi fundado em junho de 1964 e suas atribuições e estruturas foram aperfeiçoadas e significativamente ampliadas nos anos seguintes. O SNI recolhia e analisava materiais considerados relevantes para a segurança nacional do Brasil, seu chefe possuía status de ministro e seus agentes espionava organizações e indivíduos. Os relatórios e dirigentes do SNI ajudava na formulação diretrizes governamentais. Sua sede era em Brasília, havia filiais em todos os estados e territórios e faziam parte da estrutura do SNI as Divisões de Segurança e Informações (DSI), as quais estavam presentes em todos os ministérios civis vigentes. Os ministérios militares organizaram suas próprias agencias: Centro de Informações do Exército (CIE), criado em 1967 e subordinado ao ministro do Exército, o Centro de Informações de Segurança da Aeronáutica (CISA), de 1968, e o Centro de Informações da Marinha (CENIMAR), fundado em 1957 e reestruturado em 1971. Essas três seções reuniam materiais e realizavam operações de combate, prisões e torturas. O ministério das Relações Exteriores (MRE) possuía uma DSI e o Centro de Informações do Exterior (CIEX), que também lidava com assuntos internacionais. As embaixadas e demais locais de representação do Brasil no mundo frequentemente também produziam documentos. Havia troca de materiais entre os aparelhos da "comunidade de informações", embora em alguns momentos, existissem rivalidades entre eles. Todos eles colaboravam o Conselho de Segurança Nacional (CSN), um órgão do Poder Executivo presidido pelo presidente e que tinha como Secretário-geral o Chefe da Casa Militar - cujo titular também tinha status ministerial. Em linhas gerais, o CSN tinha como atribuição a defesa da segurança nacional e, posteriormente, tornou-se o centro de decisões estratégicas. Os acervos do CSN, do CIEX, do CISA e do DSI/MRE estão depositados no Arquivo Nacional e estão abertos à consulta pública (GOMES, 2014, p.91101) (JOFFILY, 2014, p.158-171).

Essa estrutura estava consolidada e contava com funcionários especializado quando os militares instalaram o PRN na Argentina, em março de 1976. A "comunidade de informações" produziu numerosos informes e relatórios sobre a situação do país nos anos anteriores da deflagração do golpe e colaboraram com ele. Outro foco de atenção eram os brasileiros que estavam exilados no país vizinho, os quais eram vistos como um perigo para ambos os Estados. Baseados nesses materiais e em outros dados, a deposição da presidenta Maria Estela Perón e a organização de um regime ditatorial foram bem recebidos pelo governo Geisel e o ministro da Marinha dessa gestão, almirante Geraldo de Azevedo Henning, foi o primeiro representante de um Estado estrangeiro a visitar o novo poder constituído na Argentina.

Posteriormente, as autoridades ditatoriais do Brasil colaboraram com a violenta repressão argentina, inclusive favorecendo a realização de operações no território brasileiro. Houve também apoio econômico e diplomático ao PRN. Todos esses atos foram motivados por um dos pilares da DSN: a ideia de que a ordem interna e a prosperidade econômica do Brasil dependiam da vigência de sociedades capitalistas e com instituições políticas análogas às brasileiras no continente americano. Por esses motivos, o regime ditatorial considerava legítimo intervir em outros Estados a fim de afastar da arena política indivíduos e grupos considerados inimigos dos interesses ditatoriais brasileiros. Outra faceta dessa visão foi o estabelecimento de laços de cooperação com forças conservadoras e com o aparato repressivo de outros países. Essas noções têm sido conhecidas como "Fronteiras Ideológicas" e baseados nessas diretrizes o Brasil colaborou ativamente com a instalação de ditaduras na Bolívia, Uruguai e Chile, participou de operações com os organismos de 
informação e repressão de outros países - como a Operação Condor -; e manteve ativo intercambio com as elites ditatoriais sul-americanas (BANDEIRA, 1995, p.213-249) (ASSUMPÇÃO, 2014, p.135-141)

Outro ponto importante no ideário de parte dos dirigentes ditatoriais era a concepção de que regimes autoritários excessivamente herméticos e repressivos poderiam favorecer irrupções sócio-políticas que desaguariam em regimes de esquerda, tais quais o colapso da ditadura autodenominada Revolución Argentina - que foi instalada em 1966, começou a ser desmantelada a partir de 1966 e foi finalmente substituída por um governo peronista -; e a eclosão da Revolução dos Cravos em1974, a qual foi liderada por militares de esquerda e ainda auxiliou o estabelecimento de governos socialistas em antigas colônias lusas de Angola e Moçambique. Segundo os adeptos desse pensamento, para evitar a substituições de governos autoritários por regimes de esquerda era necessário promover aberturas políticas a fim de estabelecer formas de democracia com pouca participação popular, dotada de instituições capazes de preservar as reformas socioeconômicas estabelecidas no período autoritário e com um nível de competição política entre as elites capaz de evitar que as disputas políticas erodissem o sistema como um todo.

Essas questões orientaram os funcionários da "comunidade de informações" que elaboraram os escritos sobre a Argentina, assim como os líderes do governo Figueiredo. A iminência da visita do presidente brasileiro a Buenos Aires em março de 1980 elevou a quantidade de materiais produzidos e nos informam a visão brasileira acerca do PRN. Em linhas gerais, o governo militar argentino na passagem da década de 1970 para os anos 1980 era politicamente caracterizado como bastante polarizado e dotado de uma cúpula militar dividida entre as alas "moderada" e "dura", as quais coexistem em função da necessidade de preservar a unidade castrense. Os chefes do PRN se destacaram também por terem suspendido as atividades partidárias, pela vitória que obtiveram no que foi chamado de "luta anti-subversiva" - fato elogiado pelos agentes da comunidade de informação - e por terem banido as agremiações e partidos de extremaesquerda - com exceção do Partido Comunista Argentino (PCA). Por outro lado, as divulgações de inúmeras denúncias referentes à participação de agentes do Estado na repressão estava sendo outro importante fator de instabilidade na ditadura argentina no período em questão. Esse conjunto de elementos estavam impedindo a realização de um sólido processo de restauração de um regime representativo na Argentina porque as disputas no interior do núcleo dirigente fomentavam incertezas entre os demais atores políticos.

Os funcionários do aparelho repressivo também produziram informes sobre a política externa do PRN e suas principais conclusões foram que a imagem argentina estava negativa perante a comunidade internacional em razão da apresentação de constantes denúncias de violências perpetradas por agentes do Estado, em função do mau desempenho dos diplomatas e demais responsáveis pela imagem do país em combater as informações contrárias ao governo militar e pela ação organizada por parte dos "grupos subversivos" que atuavam a fim de prejudicar a Argentina internacionalmente a partir de calúnias e desinformações. Uma exceção nesse quadro de desprestígio mundial eram os excelentes laços com a URSS, cujas bases principais de relação estavam ancoradas no setor comercial e estavam se expandido para setores como o militar. De acordo com os documentos brasileiros, os soviéticos se abstiveram em fazer críticas abertas ao regime argentino no que diz respeito a repressão (V8.MIC, GNC.AAA.77103439. 1977, p.01-13) (Z4 REX IPS 31, 1977-1978).

Os analistas do DSI/MRE e do CIEX receberam positivamente a sucessão do general Jorge Videla na presidência da República pelo general Roberto Viola em 1981 porque consideraram que tal processo foi fruto de um compromisso entre os três ramos das FFAA, garantiu a continuidade da ala moderada no comando do PRN e ajudou a reduzir o poder militar que eles - os funcionários da "comunidade de informações" - chamavam de ala radical (sic) das forças armadas no interior do regime. Outros pontos mencionados é que o general Viola era respeitado entre os seus pares por seu 
profissionalismo e que continuaria os parâmetros existentes no governo Videla, sobretudo aqueles vinculados à Transição Política e ao relacionamento com o Brasil.

Por outro lado, a ascensão do general Galtieri significou, para os brasileiros, que algumas tendências que eles consideravam extintas ou pouco importantes na dinâmica política argentina ainda eram relevantes. Por exemplo, a força do personalismo nas altas esferas do comando militar e do governo. A força da ala radical e a capacidade dela de promover as mudanças abruptas nos rumos do governo também foi um aspecto destacados nos materiais consultados. Outros elementos acentuados nesses mesmo escritos era que o PRN não estava suficientemente institucionalizado, uma vez que havia a possibilidade de rupturas súbitas, e a surpresa perante a atitude de Galtieri, o qual era percebido como um militar moderado, amigo do general Viola e próximo da visão de mundo dos generais Videla, Viola e dos aliados desses (Z4 REX IPS 0045, 1980-1983; p. 165-207).

No período da gestão Galtieri, os agentes brasileiros também destacaram o surgimento de grupos políticos da extrema-direita e a associação deles com militares como almirante Eduardo Emílio Massera. O último foi um dos principais articuladores do golpe de 1976 e nessa ocasião era o comandante-em-chefe da Armada. Massera continuou nessa função nos primeiros anos do PRN, foi um dos idealizadores do aparato repressivo, aglutinou parte da ala militar sob sua órbita e se opôs às políticas públicas neoliberais. Tais práticas o colocou em rota de colisão com os generais Videla, Viola e os aliados do último. Em tal disputa, Massera acabou perdendo poderes e ficou mais isolado após deixar suas funções na Armada. Nos anos seguintes, passou a tentar organizar um partido análogo ao peronista, mas de direita. Em tal intento, ele fez contato com dirigentes da maçónica Propaganda-2 (P-2), uma organização fascista, sediada na Itália e com laços com outros grupos de extrema-direita em escala global. O revigoramento da oposição sindical também despertou as atenções dos brasileiros (REX IPS 0045, 1980-1983, p.171-233) (V8.MIC, GNC.AAA.82027757,1982, p. 03-04).

O estudo desse conjunto de fontes nos permite conjecturar como parte importante da administração ditatorial brasileira enxergava o PRN: a Argentina continuava imensamente polarizada a despeito do sucesso da luta contra os subversivos. Seu governo militar carecia de um poder centralizado e era permeado por facções que muitas vezes possuíam perspectivas políticas antagônicas. Esses grupos praticavam uma luta obstinada pelo poder e as forças vitoriosas anulavam os avanços dos seus antecessores e tomavam medidas excludentes para fortalecer seu projeto. Tais fatos geravam um grau de imprevisibilidade política que afastava a sociedade do PRN, o que enfraquecia o último. $\mathrm{O}$ insucesso das reformas econômicas era outro foco de instabilidade visto que promovia tensões sociais, afastariam o povo das forças armadas e poderiam ser instrumentalizadas pelas esquerdas radicais. Por fim, o país por um quadro não muito favorável na arena internacional. Uma das medidas tomadas para minimizar tal quadro foi se aproximar da URSS e esse ponto requer um destaque especial.

\section{AS RELAÇÕES ARGENTINA-URSS E A VISÃO DA "COMUNIDADE DE INFORMAÇÕES” SOBRE TAIS VÍNCULOS}

A chegada ao poder da Junta Militar argentina foi recebida com simpatia pela cúpula do PCA e pelas autoridades soviéticas uma vez que eles acreditavam que, embora influenciados pelas forças conservadoras, o general Videla e seus aliados dialogariam com oficiais nacionalistas, preservariam o PCA e tomariam ações que colocariam fim à crise crônica pela qual passava o país. Outro argumento usado pelos comunistas argentinos e soviéticos era que os líderes do PRN evitaram a conquista do poder pela ala mais conservadora e intransigente das forças armadas, que 
eles chamavam de "pinochetistas", e tinham condições de restaurar a democracia na Argentina em um futuro próximo. Os soviéticos, em especial, incluíram em suas estratégias as metas em manter os intercâmbios comerciais e outros acordos estabelecidos ao longo dos governos peronistas (1973 a 1976) (GILBERT, 2010, p.423-455).

Esse relacionamento com os soviéticos e com o PCA não era consensual no interior da cúpula do PRN e os grupos que conseguiram viabilizar tais compromissos defenderam suas ideias afirmando que o PCA não era uma ameaça à ordem em função de suas práticas moderadas e que o país não poderia abrir mão das exportações para a URSS. Em oposições a eles, oficiais como o general Carlos Suárez Mason e o almirante Massera agiram de diferentes formas. O primeiro tentou impedir a realização da exposição Unión Soviética Hoy-76, cuja realização foi acertada durante o governo de Maria Estela Perón. Contudo, foi impedido pelos aliados do general Videla. Massara, por sua vez, engajou-se com o general Suarez Mason a articulação de um pacto militar antissoviético que reuniria a Argentina, o Brasil, o Chile, o Uruguai e a África do Sul. Porém, ambos foram frustrados pela recusa brasileira e pela indiferença do general Videla. Outra ação do comandante em chefe da Armada e de seus subordinados foi o ataque e captura de barcos pesqueiros soviéticos que navegavam próximos às águas territoriais argentinas em setembro de 1977. Esse incidente abriu a possibilidade de uma reação soviética dura em uma conjuntura em que as relações com os EUA estavam estremecidas.

As autoridades argentinas abriram negociações e trabalharam para convencer os líderes soviéticos de que uma reação armada favoreceria os grupos que desejavam o pacto militar com países como a África do Sul e o que ocorreu era obra exclusiva de militares dissidentes e não ordens do PRN. Em tais negociações, a cúpula do governo Videla contou com a colaboração de dirigentes do PCA e de consultores soviéticos críticos do comportamento de Massera e seus aliados. Por sua vez, os representantes da URSS solicitaram contrapartidas e parte delas foram obtidas a partir da visita do ministro das Relações Exteriores da Argentina, almirante Oscar Antonio Montes, a Moscou em 1978. Em tal ocasião, foram retomadas as negociações na área de cooperação econômica e cientifica e dessas conversas foi acertada a participação soviética no complexo hidroelétrico do Paraná Médio.

Os analistas civis e militares da ditadura brasileira estiveram atentos e esses acontecimentos e produziram documentos que circularam nos altos escalões de poder. De acordo com eles, o relacionamento bilateral Argentina-URSS foi abalado pelo apresamento de navios pesqueiros búlgaros e soviéticos pela armada argentina em 1977, mas superado em razão de uma série de compromissos assinados como o convênio de assessoria técnica e financeira para o projeto hidrelétrico Paraná Médio (1978), a visita de funcionários da Comisión Nacional de Energía Atómica (CNEA) à Moscou (abril de 1980) e o acordo marítimo que foi acertado a partir da visita delegação soviética de transporte marítimo chefiada pelo Vice-Ministro da Frota Marítima da URSS, Anatoly Goldobenko (novembro de 1980).

O volume e as características das trocais comerciais entre argentinos e soviéticos foram examinados pela diplomacia brasileira, segundo a qual, no ano de 1980, a URSS era responsável pela aquisição de $6 \%$ das mercadorias exportadas pelos argentinos e era o quinto maior importador de tal país embora o intercambio crescia em relação aos parceiros tradicionais como os EUA. No ano seguinte, a superpotência socialista passou a comprar $80 \%$ das exportações da Argentina e elevou suas vendas de equipamentos e bens de capital para o país sul-americano, o qual se tornou o segundo maior parceiro comercial dos soviéticos nas Américas atrás de Cuba.

${ }^{3}$ O general Augusto Pinochet foi o principal líder da ditadura militar conservadora que existiu no Chile entre 1973-1990. No decorrer da gestão dele, o Chile foi governado de forma personalista, adotou uma pauta agressivamente anticomunista no plano interno e externo, organizou um sistema repressivo que perseguiu e matou milhares de pessoas. Sobre esse tema ver MUÑOZ (2000).

Sapienza: International Journal of Interdisciplinary Studies | Vol. 2 | n. 1 | jan-mar | 2021 | e-ISSN: 2675-9780 
Os soviéticos compravam principalmente cereais e outros produtos agropecuários. Uma observação presente nos estudos da burocracia brasileira foi que essa relação poderia se estreitar mais caso o presidente Videla fizesse uma viagem oficial para Moscou. Contudo isso não se concretizou e os argentinos também aderiram ao boicote aos jogos olímpicos de Moscou em 1980 e utilizaram seus vínculos com os soviéticos para barganhar com os estadunidenses (Z4 REX IPS 0427. 1978, p.01-43) (Z4 REX IPS 38, p.1065-1092) (Z4 REX IPS 426, 1980).

Os argentinos adquiriram toneladas de água pesada dos soviéticos para a usina nuclear Atucha I em janeiro de 1981. Em dezembro do mesmo ano, o almirante Castro Madero, presidente da CNEA, falou em uma entrevista que prosseguiam as negociações com autoridades soviéticas sobre a possibilidade dos últimos prestarem serviço de enriquecimento de urânio para os reatores das usinas nucleares argentinas e em relação aos estudos acerca da viabilidade de um acordo de assistência tecnológica na área nuclear com a URSS. Os brasileiros também acompanharam as reuniões anuais da Comissão Mista Argentino-Soviética para Cooperação Econômico-Comercial e Técnico-Científica (Z4 REX IPS 38, p.93-144) (V8.MIC, GNC.AAA.81017314, 1981, p.03-04) (Z4 REX IPE 429.1981-1982, p.168-169).

Outro tema recorrente na documentação foi a aproximação entre militares soviéticos e argentinos. Primeiramente, a presença de um adido militar na embaixada argentina em Moscou já era um elemento de destaque para alas da ditadura brasileira (Z4 REX IPS 437. 1978-1979, p.129130). Por outro lado, a novidade nesse campo foi a chegada de uma comitiva de cadetes e oficiais do Exército Vermelho comandada pelo Tenente-General de Artilharia e Tanques Ivan Jacovich Braiko. Os soviéticos visitaram instalações militares da Argentina por duas semanas de agosto de 1979 e foram recebidos por membros da cúpula do Exército argentino como o general Roberto Viola, então comandante-em-chefe e membro da Junta Militar, e o general José Montes, comandante do Institutos Militares - setor responsável pelas escolas militares. Segundo os brasileiros, essa visita foi celebrada pela imprensa da URSS. A delegação soviética foi acompanhada por técnicos responsáveis por discussões na área de infraestrutura e desportiva, assim como por membros do Circo de Moscou e por outros artistas que realizaram numerosas apresentações culturais em Buenos Aires (Z4 REX IPS 426, 1979-1980, p.153-186).

Embora os documentos brasileiros tenham caracterizado a recepção dos soviéticos em Buenos Aires como fria e protocolar, militares argentinos e soviéticos trocaram medalhas e os argentinos retribuíram a visita em outubro de 1979. O general José Montes comandou a comitiva de militares que chegou a Moscou e afirmou que seu país que desejava perpetuar os vínculos entre as duas forças armadas. Essas informações foram apresentadas em um relatório denso da "comunidade de informações", o qual também afirmou que o Secretário-Geral do comandante-em-chefe do Exército, general Reynaldo Bignone, elogiou a fala do general Montes. Por outro lado, jornais argentinos Buenos Aires Herald, La Prensa e o Die Welt, da Alemanha Ocidental, a criticaram (Z4 REX IPS 426, 1979-1980, p.154-192).

A Argentina manteve relações salutares com outros governos socialistas, como o da Romênia e da Tchecoslováquia. Por outro lado, Cuba era alvo de constantes críticas por parte das autoridades do PRN (Z4 REX IPS 38, p. 141 e p. 1092).

A significativa aproximação do PRN com a URSS deixou em alerta os dirigentes brasileiros, sobretudo em razão do aumento da participação soviética em áreas consideradas como de interesse estratégico - como o energético, o nuclear e o militar. Em segundo lugar, temia-se a crescente dependência da economia argentina em relação às suas vendas para a União Soviética. Em terceiro, de acordo com os mesmos analistas, os soviéticos poderiam infiltrar agentes responsáveis por propagar a ideologia comunista entre os funcionários que trabalhariam nos projetos binacionais, o que em longo prazo poderia desestabilizar a sociedade argentina. Os possíveis vínculos estabelecidos entre funcionários argentinos e soviéticos e a possibilidade do 
desenvolvimento de uma imagem positiva da URSS na Argentina a partir do sucesso desses empreendimentos industriais também não eram vistos com bons olhos pelos líderes do Brasil.

No que diz respeito às FFAA, o receio era a formação de um setor da oficialidade identificado com os valores da esquerda, os quais poderiam influenciar o futuro político da Argentina tal como aconteceu na Revolução dos Cravos. Igualmente, acreditava-se que os soviéticos obteriam dados compartilhados exclusivamente entre os exércitos das Américas.

\section{AS MALVINAS NO ENCONTRO ENTRE OS PRESIDENTES JOÃO FIGUEIREDO E RONALD REAGAN}

As impressões sobre a Argentina que foram discutidas anteriormente fizeram parte do documento concluído em 07 de abril de 1982 pelo SNI denominado "Ilhas Malvinas", em que foram salientados fatos como a opinião soviética de que os britânicos eram os responsáveis pelo conflito em função do colonialismo, a exortação que Moscou fez para que os povos latinoamericano se unissem aos argentinos e a possibilidade dos soviéticos prestarem apoio militar aos argentinos (V8.MIC, GNC.AAA.82027760. 1982, p.21-92).

Todas essas questões se fizeram presentes na visita oficial que o general Figueiredo e sua comitiva fizeram aos EUA em maio de 1982. Nesse momento os EUA colaboravam com os britânicos e, por isso, a delegação brasileira "reduziu seu programa de atividades e cancelou os eventos festivos, como forma de demostrar constrangimento e desacordo com a posição tomada pelos Estados Unidos" (BANDEIRA, 1995, p. 267). A equipe brasileira elaborou o texto "Visita do presidente João Baptista de Oliveira Figueiredo aos EUA. Encontros com o Secretário de Estado Haig, dia 11, e com o presidente Reagan dias 12 e 13" que norteou as conversas com os líderes estadunidenses.

Em linhas gerais, as autoridades brasileiras alegaram que eram contrárias à invasão militar e que não foram consultadas previamente pelo governo argentino. Do mesmo modo, argumentaram que a Argentina não poderia ser acuada pelos britânicos, isolada internacionalmente ou tampouco deveria ser derrotada de uma forma humilhante porque tais desfechos desestabilizariam o regime militar vigente e favoreceriam a ascensão política dos militares nacionalistas ou, no pior dos casos, a substituição do PRN por um governo peronista, o qual possivelmente seria sucedido por um governo comunista. Segundo os termos do documento, ambas as possibilidades favoreceriam os soviéticos porque os militares nacionalistas buscariam apoio bélico e tecnológico juntos aos soviéticos. No caso dos peronistas, os comunistas teriam liberdade para propagar sua ideologia, para tomar o poder e colocar a Argentina na órbita de Moscou, assim como já estavam países como Cuba e Angola.

Assim, os brasileiros insistiram que os EUA deveriam interceder junto à comunidade internacional para evitar o colapso total da Argentina ou que o isolamento desse país o levasse a recorrer à ajuda militar de cubanos e soviéticos. Outro argumento foi que seria ruim para o ocidente o desenvolvimento de sentimento anti-britânicos e anti-estadunidenses em todos os países latinoamericanos, o que também favoreceria as esquerdas do continente. De acordo com o mesmo texto, tais conjecturas só seriam evitadas caso os britânicos decidissem não bloquear os portos argentinos, não bombardear alvos fora das Malvinas e tampouco aniquilasse as tropas argentinas nos arquipélagos (N8_PSN_EST_0288, 11-13.05.1982, p. 24-27).

No decorrer das discussões, Secretário de Estado Alexander Haig afirmou que os EUA também acreditavam que cubanos e soviéticos estavam usando sua ajuda à Argentina como pretexto 
para aumentar suas influências em tal país. No dia seguinte, as conversas com o presidente Reagan foram análogas, exceção de que Figueiredo citou a importância da prosperidade e da estabilidade da Argentina e da América Latina para o bem-estar do Brasil (N8_PSN_EST_0288, 11-13.05.1982, p. 01-27).

\section{CONSIDERAÇÕES FINAIS}

No dia 14 de junho de 1982 o general Mário B. Menendez, comandante das tropas argentinas nas Malvinas, rendeu-se aos britânicos. No dia seguinte, o povo foi convocado para receber as notícias e o esclarecimento da situação gerou uma revolta anti-ditatorial. Paralelamente à transformação do centro da cidade de Buenos Aires e adjacências em um campo de batalha, um colegiado de generais-de-divisão destituíram o general Galtieri da presidência e do comando do Exército com os argumentos de que o presidente não consultou a oficialidade na deflagração da guerra e na condução das negociações com os americanos e britânicos. Nos dias seguintes, esses generais designaram o general Cristino Nicolaides para a presidência da República e o general Reynaldo Bignone para o comando do Exército. Ambos os generais guiaram os rumos políticos da Argentina nos meses seguintes e se esforçaram para promover um processo de transição da ditadura para um futuro regime democrático onde as esquerdas não tivessem força e em que os militares envolvidos na repressão política do PRN não fossem punidos. No ano seguinte, as esquerdas perderam as eleições presidenciais para Raúl Alfonsín, da Unión Cívica Radical (UCR). Em seu mandato os líderes da repressão ditatorial foram julgados e vários deles foram presos (BANDEIRA, 1995, p. 269-272).

No que diz respeito ao Brasil, o fim do conflito foi bem recebido por parcelas do governo Figueiredo, como os ministros Leitão de Abreu (Justiça) e o almirante Maximiano da Fonseca (Marinha). Para esses setores, houve uma paz honrosa para a Argentina (JB, 15.06.1982, p. 12). No interior dos órgãos de vigilância, as análises sobre a situação argentina continuaram. Em um primeiro momento, os textos demonstram uma certa apreensão em virtude da imposição de Bignone na presidência ter contrariado os interesses da Armada e da Força Aérea Argentina. Todavia, na medida em que os generais Nicolaides e Bignone consolidaram suas posições, os documentos brasileiros maior tranquilidade em relação aos rumos que a Argentina estavam tomando (N8_PSN_EST_105, 1970-1989, p. 633-660) (V8.MIC, GNC.AAA.82027760, 1982, p. 172-194) (2M.0.0.71, v.3, 1982-1983, p. 122-123) (V8.MIC, GNC.AAA.84040574, 1983, p. 01-02). Nos anos seguintes, as iniciativas brasileiras nas Malvinas foram decisivas no processo de apaziguamento das relações com a Argentina e ajudaram a "pavimentara" o caminho que levou a criação do Mercado Comum do Sul (MERCOSUL), em 1988, e em uma série de acordos econômicos.

No decorrer das páginas desse trabalho, estudamos a literatura produzida sobre as causas da adoção da chamada "neutralidade imperfeita" por parte do governo do general João Figueiredo e, diferente da maior parte dos estudos, trabalhamos com o pressuposto de que a cúpula brasileira tinha como objetivo evitar que uma derrota argentina acachapante criasse condições para a derrubada do PRN e a substituição do último por um governo de esquerda, o qual, potencialmente favoreceria as oposições de esquerda à ditadura brasileira. Desta forma, de acordo com esse trabalho, o general Figueiredo e seus aliados estavam preocupados também com a ordem interna do Brasil e dos países vizinhos - os quais também eram governados por formas ditatoriais de direita uma vez que eram guiados pelo pensamento oriundo da Doutrina de Segurança Nacional e de normas como a das "Fronteiras Ideológicas". Por esses motivos, este trabalho contribui com outros estudos da historiografia e relações internacionais voltados para as relações exteriores entre os 
países sul-americanos - tais como Munõz (1986), Escudé e Cisneros (2000) e Lechini (2006) -; para a aplicação da DSN na política externa brasileira - Vizentini (2006), Bandeira (2008) e Padrós (2010) -; para as pesquisas sobre a integração entre Argentina e Brasil - Cervo (1994), Bandeira (1995) e Velasco Júnior (2015) - além daqueles dedicados à compreensão da Guerra das Malvinas e que foram discutidos nesse ensaio.

Examinamos diferentes documentos produzidos pela "comunidade de informação" para comprovar as hipóteses desse ensaio e pudemos perceber que esse setor foi um ator político que agiu no quadro interno, como aponta estudos de Fico (2007) e Gomes (2014), mas também nas relações exteriores brasileiras. Nesse processo, o grupo em questão elaborou uma narrativa sobre a ditadura argentina, sobre os perigos da aproximação com os soviéticos e também sobre a ditadura brasileira. Os limites desse ensaio impossibilitam um estudo mais aprofundado sobre esse caso, mas cabe citar que o regime brasileiro é apresentado como superior e paradigmático em relação ao vizinho pela estabilidade, por ter iniciado com êxito um processo de reestabelecimento de um governo representativo, pelo respeito que obteve junto à comunidade internacional de países. Desta maneira, esse ensaio também colabora com o campo de estudos do aparelho de informações da ditadura brasileira.

As declarações das autoridades do governo Figueiredo e os relatórios da espionagem nos levam a crer que as metas almejadas quando houve a adoção da "neutralidade imperfeita" foram atingidas. Contudo, os detalhes da forma como os escritos da comunidade de informações foram assimilados pela cúpula ditatorial brasileira não puderam ser abordados nesse trabalho por diferentes motivos. Em primeiro lugar, a própria natureza do material fez com que seus leitores não assumissem a existência de tais termos em suas memórias. Igualmente, não temos dados sobre quem eram os informantes dos funcionários brasileiros e tampouco o material por eles consultados para elaborar os relatórios e demais informes. Sabemos que geralmente eram jornalistas locais e estrangeiros, assim como adidos militares. Todavia, essas informações são ínfimas e atrapalham o detalhamento dos interesses envolvidos ao passar esclarecimentos para os agentes do Brasil: quem eram eles? Por que razões passavam informações? Essas e outras perguntas não podem ser respondidas nesse momento. Um terceiro limite teórico-metodológico desse ensaio advém do nosso desconhecimento sobre se as reflexões compartilhadas pela comitiva do general Figueiredo tiveram influência nos destinos da guerra. Empiricamente, os britânicos se limitaram a retomar os arquipélagos ocupados. Contudo, não houve a necessidade de aprofundar a guerra pois, como estudos como o de Lopes (2012) têm demonstrado, havia um grande despreparo por parte da Argentina para o conflito que travou.

Por último, cabe-nos propor futuras pesquisas e abordagens relacionadas com essa discussão. Estudos sobre a ação dos serviços de informações britânicos e dos EUA no conflito, assim como a forma eles interpretavam a estrutura política do PRN e dos laços dessa ditadura com a URSS são as nossas primeiras recomendações. Outras sugestões dizem respeito à possibilidade do estudo do olhar militar sobre os acordos estabelecidos com a Argentina governada por Alfonsín uma vez que essa gestão julgou os oficiais responsáveis pela repressão política. Pesquisar a participação da "comunidade de informações" na tomada de decisão de outros temas da política externa brasileira também pode ser um caminho promissor de pesquisas de uma ditadura em diversos momentos interveio nos rumos dos países vizinhos a fim de garantir sua própria estabilidade e permanência.

\section{REFERENCIAS}

2M.0.0.71, v.3. Operação Rosário (cont) - retomada das ilhas Malvinas - Dossiê. Arquivo Nacional. Fundo: Estado-Maior das Forças Armadas. Brasília:1982-1983 
ASSUMPÇÃO, Marla B. A noção de fronteiras ideológicas e a dimensão internacional civil-militar brasileira. In: GALLO, Carlos A.; RUBERT, Silvania. Entre a memória e o esquecimento: estudos sobre os 50 anos do golpe civil-militar no Brasil. Porto Alegre: Editora Deriva, 2014. Cap. 7, p. 135-154

BANDEIRA, Luis A. Moniz. Estado nacional e política internacional na América Latina. O continente nas relações Argentina - Brasil (1930-1992). São Paulo: Ensaio, 1995.

Civilização Brasileira, 2008.

Fórmula para o caos: ascensão e queda de Salvador Allende (1970-1973). Rio de Janeiro:

CAMILIÓN, Oscar. Memorias politucas. De Frondizi a Menem (1956-1996). Buenos Aires: Editorial Planeta Argentina, 1999.

ESPÓSITO NETO, Tomaz. A Política Externa Brasileira frente ao conflito das Falklands/Malvinas (1982). 2006. 189p. Dissertação (Mestrado em História) - Pontifícia Universidade Católica de São Paulo, São Paulo, 2006.

EL PAÍS. Brasil apoyó el envío de armas a Argentina durante la guerra de las Malvinas. Eı País, Madrid. 22.04.2012 https://elpais.com/internacional/2012/04/22/actualidad/1335130850 563632.html <Acesso em 15.03.2021〉.

ESCUDÉ, Carlos; CISNEROS, Andrés. Capítulo 68: El régimen militar (1976-1983). Las relaciones con los países latino-americanos: Las relaciones con Brasil. Historia General de las Relaciones Exteriores de la Argentina (1806 - 1989). Buenos Aires. Consejo Argentino para las Relaciones Internacionales (CARI), 2000. http://www.argentina-rree.com/14/14-015.htm Consulta em 25.02.2021.

FERREIRA, Túlio; FORTES, Clarice. O Brasil e a guerra das Malvinas - uma análise do processo decisório brasileiro. In: Revista Conjuntura Austral. v. 11, n. 54, p. 123-140, abr./jun. 2020.

FICO, Carlos. Espionagem, polícia política, censura e propaganda: os pilares básicos da repressão. In: FERREIRA, Jorge; DELGADO, Lucilia A. N. O Brasil Republicano. Vol. 4. O tempo da ditadura. Rio de Janeiro: Civilização Brasileira, 2007, p. 45-65.

FILMUS, Daniel F. Brasil-Argentina y la Cuestión de las Islas Malvinas. Del histórico apoyo a una política común. Revista Landa. Vol. 4. Nº1. p. 348-368. 2015.

GILBERT, Isidoro. O ouro de Moscou. Rio de Janeiro: Record, 2010.

GOMES, Paulo C. Os bispos católicos e a ditadura militar brasileira (1971-1980): a visão da espionagem. Rio de Janeiro: Record, 2014.

GUERREIRO, Ramiro S. Lembranças de um empregado do Itamaraty. São Paulo: Siciliano, 1992.

JB. Governo brasileiro concede agrément a Oscar Camilión, novo embaixador argentino". Jornal do Brasil, Rio de Janeiro. 22.05.1976, p. 08 [a].

Um especialista em política brasileira. Jornal do Brasil, Rio de Janeiro.22.05.1976, p. 08 [b]. . A América Latina nuclear". Jornal do Brasil, Rio de Janeiro. 30.01.1977, p. 06 Cad. Especial. Brasil acha desrespeitoso projeto da OEA. Jornal do Brasil, Rio de Janeiro, 24.06.1977, p. 08. . OEA repudia tortura e atos de terrorismo. Jornal do Brasil, Rio de Janeiro, 02.07.1978, p. 14. 17.01.1980, p. 21 Embaixador elogia Brasil por não aceitar boicote à URSS. Jornal do Brasil, Rio de Janeiro,

Moscou teme bloqueio e promete dar ajuda. Jornal do Brasil, Rio de Janeiro, 07.04.1982, p. 13 [b]. . Figueiredo oferece mediação para evitar a guerra. Jornal do Brasil, Rio de Janeiro, 11.04.1982, p. 12 FAB intercepta Illyshin com embaixador cubano. Jornal do Brasil, Rio de Janeiro, 11.04.1982, p. 15. . Brasil decide ajudar Argentina no campo econômico. Jornal do Brasil, Rio de Janeiro, 12.04.1982, p.

12

Brasília e B. Aires se entendem em segredo. Jornal do Brasil, Rio de Janeiro, 13.04.1982, p. 13. Costa Mendez agradece a solidariedade do Brasil. Jornal do Brasil, Rio de Janeiro, 03.06.1982, p. 13 Fim da guerra agrada Brasil. Jornal do Brasil, Rio de Janeiro, 15.06.1982, p. 12.

JOFFILY, Mariana. O aparato repressivo: da arquitetura ao desmantelamento. In: REIS FILHO, Daniel A; RIDENTI, Marcelo; SÁ MOTTA, Rodrigo. A ditadura que mudou o Brasil: 50 anos do golpe de 1964. Rio de Janeiro: Zahar, 2014. Cap. 9, p. 158-171.

LECHINI, Gladys. Argentina y África en el espejo de Brasil: ¿política por impulsos o construcción de una política exterior? 1a ed. - Buenos Aires: Consejo Latinoamericano de Ciencias Sociales - CLACSO, 2006.

LOPES, Roberto. $\mathrm{O}$ código das profundezas: coragem, patriotismo e fracasso a bordo dos submarinos argentinos nas Malvinas. Rio de Janeiro: Civilização Brasileira, 2012 
MARTINEZ, Hugo. O outro lado das Malvinas. In: CABRAL, Antônio et.al. Guerra Santa nas Malvinas. São Paulo: Global, 1983.

MÉNDEZ, Nicanor. Malvinas: esta es la historia. Buenos Aires: Editorial Sudamericana, 1993.

MUÑOZ, Heraldo. A América Latina e a política mundial. São Paulo: Convívio, 1986. A sombra do ditador: memórias políticas do Chile sob Pinochet. Rio de Janeiro: Zahar, 2000.

N8_PSN_EST_105. Argentina (diversos). - Dossiê. Arquivo Nacional. Fundo: Conselho de Segurança Nacional. Brasília:1970-1989.

N8_PSN_EST_0288. Viagem do presidente aos EUA. - Dossiê. Arquivo Nacional. Fundo: Conselho de Segurança Nacional. Brasília: 11-13.05.1982

N8_PSN_EST_0288. Viagem presidencial à Argentina em 1980. Arquivo Nacional. Fundo: Conselho de Segurança Nacional. Brasília: 1972-1980.

O GLOBO. Ilhas Malvinas: Brasil apoiou tráfico de armas para Argentina. O Globo, Rio de Janeiro. 21.04.2012. https://oglobo.globo.com/brasil/ilhas-malvinas-brasil-apoiou-trafico-de-armas-para-argentina-4707825 Acesso em 15.03.2021.

PADRÓS, Enrique [et. al.]. A Ditadura de Segurança Nacional no Rio Grande do Sul (1964-1985): história e memória. Vol. 03. Porto Alegre: Corag, 2010.

SANHUEZA, Raúl. Desbrozando mitos: América Latina y Chile ante la Guerra del Atlántico Sur. Revista política y estratégia. V. 59, No 122, p. 59-78. Diciembre 2013.

V8.MIC, GNC.AAA.77103439. “Argentina luta militar contra guerrilha”. Arquivo Nacional. Fundo: Serviço Nacional de Informações. Brasília: 1977, p.01-13

V8.MIC, GNC.AAA.81017314. "Argentina, União Soviética. V reunião da comissão mista argentinosoviética. Cooperação energética”. Arquivo Nacional. Fundo: Serviço Nacional de Informações. Brasília: 1981.

V8.MIC, GNC.AAA.82027757. "Loja maçônica propaganda 2 p2. Licio Gelli. Vinculações no Uruguai e na argentina. Relação de maçons uruguaios”. Arquivo Nacional. Fundo: Serviço Nacional de Informações. 1982.

V8.MIC, GNC.AAA.82027760. “Ilhas Malvinas”. Arquivo Nacional. Fundo: Serviço Nacional de Informações. Brasília: 1982.

V8.MIC, GNC.AAA.84040574. Argentina. As últimas militares. - Dossiê. Arquivo Nacional. Fundo: Serviço Nacional de Informações. Brasília, 1983.

VELASCO JÚNIOR, Paulo A. M. Os empresários no Mercosul: distância ou participação? Mural Internacional, [S.1.], v. 6, n. 2, p. 186-201, jun. 2016

VIDIGAL, Carlos Eduardo. Uma questão de confiança: o Brasil diante da guerra das Malvinas. Anais do 3 Encontro da ABRI. São Paulo, 2011.

VIZENTINI, Paulo G. F. O regime militar brasileiro e sua política externa. In: MARTINS FILHO, João R (Org.). O golpe militar de 1964 e o regime militar. São Carlos, Edufscar, 2006.

WALSH, Marcelo. A atuação do Brasil frente à crise das Malvinas/Falklands (1982). 1997. 182p. Dissertação (Mestrado em História). Universidade de Brasília (UNB), Brasília, 1997.

Z4 REX IPS 31. “Argentina - relações com o Brasil”. Arquivo Nacional. Fundo: Divisão de Segurança e Informações do Ministério das Relações Exteriores. Brasília: 1977-1978.

Z4.REX.IPS.38. “Argentina - política externa”. Arquivo Nacional. Fundo: Divisão de Segurança e Informações do Ministério das Relações Exteriores. Brasília: 1980-1980.

Z4 REX IPS 39 - argentina - relações com o brasil. - Dossiê. Arquivo Nacional. Fundo: Divisão de Segurança e Informações do Ministério das Relações Exteriores. Brasília: 22.03.1973

Z4 REX IPS 40 - argentina - relações com o brasil. - Dossiê. Arquivo Nacional. Fundo: Divisão de Segurança e Informações do Ministério das Relações Exteriores. Brasília: 31.07.1973.

Z4 REX IPS 41 - argentina - relações com o brasil. - Dossiê. Arquivo Nacional. Fundo: Divisão de Segurança e Informações do Ministério das Relações Exteriores. Brasília: 24.04.1980.

Z4 REX IPS 0045, “Argentina - Política Interna”. Arquivo Nacional. Fundo: Divisão de Segurança e Informações do Ministério das Relações Exteriores. Brasília: 1980-1983. 
Z4 REX IPS 230. "Peru. Conflito Anglo-argentino”. Arquivo Nacional. Fundo: Divisão de Segurança e Informações do Ministério das Relações Exteriores. Brasília: 07.07.1982

Z4 REX IPS 426. “Dossiê”. Arquivo Nacional. Fundo: Divisão de Segurança e Informações do Ministério das Relações Exteriores. Brasília: 1980

Z4 REX IPS 0427. "Dossiê". Arquivo Nacional. Fundo: Divisão de Segurança e Informações do Ministério das Relações Exteriores. Brasília: 1978.

Z4 REX IPE 429. “Dossiê”. Arquivo Nacional. Fundo: Divisão de Segurança e Informações do Ministério das Relações Exteriores. Brasília: 1981-1982

Z4 REX IPS 437. "Dossiê". Arquivo Nacional. Fundo: Divisão de Segurança e Informações do Ministério das Relações Exteriores. Brasília: 1978-1979. 